\title{
Covid-19: trainees will not move jobs in April
}

\author{
Abi Rimmer
}

The BMJ

Postgraduate trainees will not rotate to new roles on 1 April as previously planned because of the covid- 19 pandemic, training organisations have announced.

A joint letter to trainees from the four UK training bodies and the General Medical Council said that postgraduate medical trainees would make a major contribution to the NHS during the covid-19 pandemic. It said that the next planned rotation of postgraduate medical trainees would involve over 20000 doctors across the UK at a time when the NHS would be facing an increasing burden due to covid-19.

"It has therefore been decided that all planned rotations due to take place during the 'delay phase' of covid-19 will cease, with trainees being asked to stay in their present working environment, unless local arrangements allow otherwise or wider clinical circumstances require it," the letter said. "Rotations may only occur where departmental inductions, appropriate supervision, and support can be guaranteed."

The letter said that retaining trainees in their current placements would enable them to build on the skills they have developed at a time when there is likely to be a sizeable requirement for all of the workforce to use all their professional capabilities.

But there are two potential exceptions. Firstly, trainees could be deployed to areas of major clinical need, the letter said. Secondly, in any areas and specialties where rotation is possible without creating issues, it will be discussed.
To minimise the effect that this decision will have on trainees' ability to attain the capabilities they need to progress in their training, the training bodies said that they would ensure that the circumstances were taken into consideration in the annual reviews of competency progression and in recruitment and selection processes. "We will also work with NHS service providers to ensure education and training requirements are delivered after this difficult period," the letter said.

Sheona MacLeod, deputy medical director for education reform at Health Education England (HEE) said, "HEE is working with partners including the devolved nations, GMC, NMC [Nursing and Midwifery Council], [NHS England and NHS Improvement], and universities to ensure we are doing everything we safely can to maximise the contribution current students and trainees can and will make to frontline services and dealing with the coronavirus (covid-19) outbreak."

The letter was co-signed by Pushpinder Mangat, medical director at Health Education and Improvement Wales; Keith Gardiner, chief executive and postgraduate dean at the Northern Ireland Medical and Dental Training Agency; Rowan Parks, acting medical director of NHS Education for Scotland; Sheona MacLeod, deputy medical director for education reform at HEE; and Colin Melville, medical director and director of education and standards at the GMC. 